\title{
The effect of flowering date and temperature on embryo development in sweet cherry (Prunus avium L.)
}

\author{
J. P. Braak \\ Institute for Horticultural Plant Breeding (IVT), Wageningen, the Netherlands
}

Key words: sweet cherry, Prunus avium, embryo development, embryo abortion, flowering date, temperature

\section{Summary}

The incapacity for germination which is associated with an incomplete embryo development in early ripening varieties of the sweet cherry (Prunus avium L.) presents a drawback to the breeding of early varieties. It was found that both a retardation of the flowering date and a low temperature during embryo growth have an adverse effect on embryo development. This may lead to the production of underdeveloped embryos and, as a consequence, to a lack of germination ability. This phenomenon is particularly common in early ripening varieties. By placing the mother trees in a glasshouse held at a temperature of over $18{ }^{\circ} \mathrm{C}$ from the date of flowering to the completion of embryo growth, embryo abortion can to a large extend be prevented. This may contribute to more efficient breeding for earliness in the sweet cherry.

\section{Introduction}

The failure of seed of early stone fruit varieties to germinate is well known and is a serious handicap in any breeding project aimed at the production of new early varieties.

Tukey (1933a) established that the poor germinability of the seed of early sweet cherries is caused by inadequate endosperm formation and abortion of the embryo. These embryos have been inhibited in their development but they retain their viability for some time. Tukey was the first to overcome the germination difficulties by raising full-grown seedlings from these underdeveloped embryos by means of embryo culture, first with sweet cherry (Tukey, 1933b), later also with other stone fruits (Tukey, 1934, 1938).

In subsequent years other investigators using Tukey's method of embryo culture also succeeded in growing plants from aborted embryos of early stone fruit varieties, but like Tukey they found that success depended on the size of the embryo. This applied both to early peaches (Davidson, 1933, 1934; Lammerts, 1942) and to early sweet cherries (Danielson, 1951). Although it proved possible to improve the ger- 
mination of embryos by special pre-treatment of the fruit, the seed or the embryo (Lesley \& Bonner, 1952; Kester \& Hesse, 1955; Hesse \& Kester, 1955; Remy, 1961) and to increase the percentage of normal seedlings by perfecting the culture of embryos and of planted seedlings (Lammerts, 1943; Braak, 1955; Remy, 1961; Theiler, 1971; Abou-Zeid et al., 1972), yet the germination of the very small embryos from the seed of the earliest varieties proved to be impossible.

At the request of and in collaboration with the Fruit Department of the Institute the present author started in 1951 to apply embryo culture as part of a breeding project aimed at raising better early sweet cherry varieties for Dutch conditions (Braak, 1955). And although in this manner progenies from different crosses were obtained, the output proved to be too small for an efficient breeding programme. Therefore it was decided to look for an alternative method.

Embryo culture is used to overcome abortion of the embryo that has already occurred. However, it is also conceivable that embryo abortion can be fully or partly prevented by treatment of the mother plant prior to or during embryo development, for instance by influencing the mother tree by application of chemical substances (growth regulators) or through factors of the environment (light, temperature).

That real possibilities for achieving this do exist may be concluded from a communication by Stösser (1966). He remarked that an extremely early cherry variety which almost entirely produced aborted embryos under the conditions of Geneva, New York (Tukey, 1933a), yielded normal embryos in the climate of California (Lilleland \& Newsome, 1934).

The present paper reports on an investigation on the effect of the environment on embryo development in sweet cherry. As certain essential parts of the problem could only be efficiently examined thanks to the facilities of our phytotron, publication of the results of our study in this jubilee issue seemed appropriate.

\section{The relation between embryo quality and the duration of fruit development}

For a good understanding of the phenomenon of embryo abortion in early stone fruits it is useful to examine more closely the development of the fruit, seed and embryo. It appears that with normal embryo development, as occurs in late ripening varieties, three successive, well-marked phases can be distinguished:

- Phase I: rapid growth of the fruit (pericarp) and the seed (nucellus), no appreciable growth of the embryo;

- Phase II: delay or cessation of fruit growth, rapid growth of the embryo which reaches its final size at the end of this phase, hardening of the stone (endocarp);

- Phase III: resumption of the growth of the fruit and ripening of the fruit flesh (exocarp).

This cyclic development appears to be characteristic of late ripening varieties of peach, plum, sour cherry and has also frequently been described for sweet cherry, among others by Tukey (1933a), Braak (1955), Willing (1960) and Stösser (1966).

The situation in early varieties differs from that described above in that the pause in fruit growth in phase II is markedly shortened or, as in very early varieties, does not occur at all. In the latter extreme case the second part of the growth and of the 


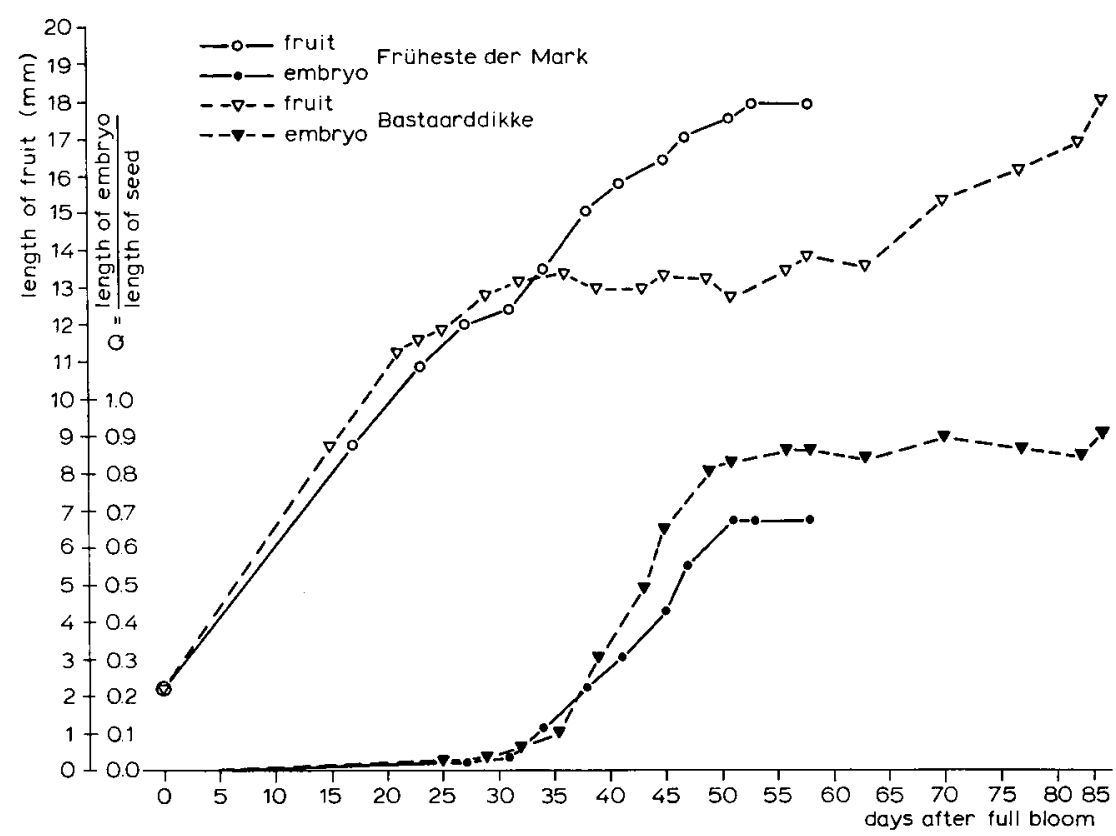

Fig. 1. Growth curves of the fruit (length in $\mathrm{mm}$ ) and the embryo (developmental index $\mathrm{Q}$ ) of an early (Früheste der Mark) and a late variety (Bastaarddikke) of the sweet cherry.

ripening of the fruit coincides with the phase of rapid growth of the embryo, with the result that the embryo can hardly reach its full size at the time the fruit is ripe (Fig. 1). From this it follows that any delay in the normal rate of development of the embryo will result in an underdeveloped embryo at the time of fruit ripeness. With a late ripening variety this risk will be much smaller, as in this case, despite a delay, the embryo will be able to complete its development, because the ripening period of the fruit is longer.

The definition of the three phases can be based on fruit development, as was done above, but also on embryo development. In a late ripening variety the phases of both definitions will practically coincide. With an extremely early variety, however, phase II will be absent if defined on fruit development, phase III if defined on embryo development. In the present study embryo development was chosen for defining the developmental phases.

\section{Material and methods}

As mentioned earlier, it was the object of this study to find a relation between environmental factors and embryo development. As a criterion of the progressing development the increase in embryo length was chosen. To permit a comparison of varieties with different seed sizes, the ratio between the length of the embryo and that of the seed was taken as a measure of the successive developmental stages. 
This quotient $\mathrm{Q}=$ length of embryo/length of seed will hereafter be indicated as the developmental index (Hesse \& Kester, 1955).

Each individual assessment of these $Q$ values depended on measurements on a sample of on average 30 seeds. The fruit samples were collected in the Institute's experiment garden at Elst, $10 \mathrm{~km}$ south of Arnhem, where a large collection of cherry varieties was available. After removal of the fruit flesh and cracking of the stones the seeds were kept overnight in running tap water. The next day the lengths of seed and embryo were measured and the mean value of the developmental index calculated.

The temperature data used were derived from temperature records at the experiment garden at Elst. These figures, if necessary, were corrected with the aid of data supplied by the Department of Physics and Meteorology of the Agricultural University at Wageningen and by the KNMI (Royal Netherlands Meteorological Institute) at De Bilt.

\section{Effect of flowering date}

An examination over a range of years of the embryo quality data obtained from the varieties present at Elst revealed the existance of appreciable differences between the years for the separate varieties. In some years even early varieties were able to produce appreciable numbers of almost fully grown embryos, whereas in other years late ripening varieties sometimes showed distinct embryo abortion. These phenomena might be an indication of an effect of one or more climatic factors on embryo development.

Comparison of available figures on embryo quality and certain phenological data

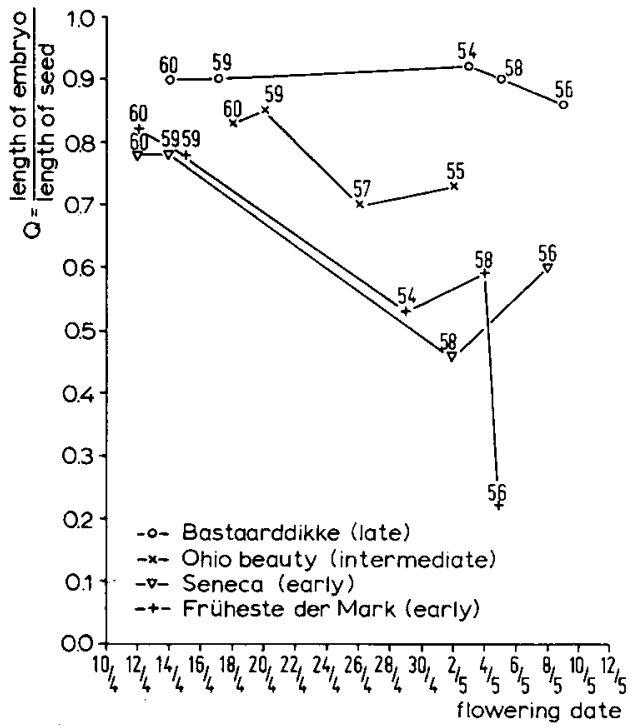

Fig. 2. The relation between developmental index ( $Q$ value) of the embryo at fruit and the date of flowering for four varieties of sweet cherries in the period 1954-1960. 


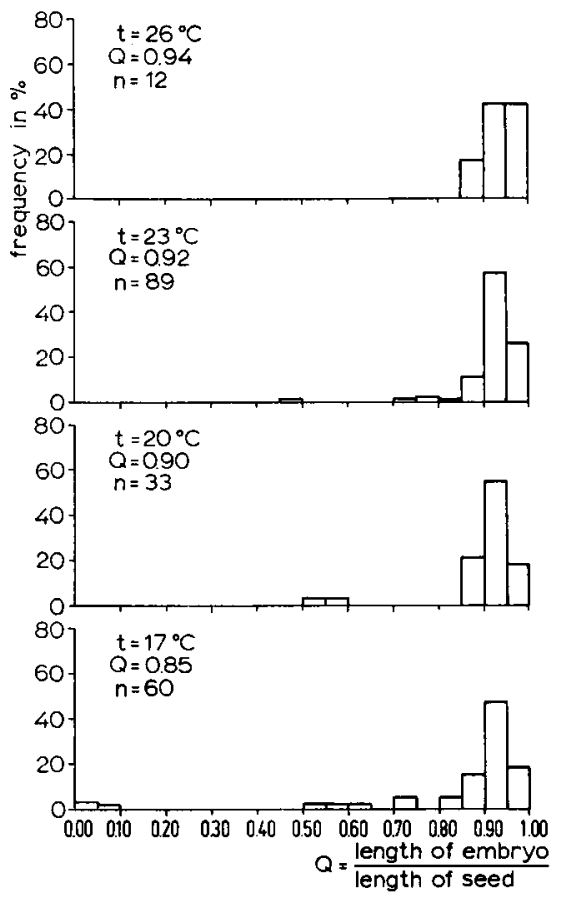

Fig. 3. The distribution of developmental index classes ( $Q$ values) of embryos of the early variety Kassin's Frühe grown at 4 constant temperatures. $\mathrm{t}$ : temperature; $\mathrm{Q}$ : mean developmental index; $\mathrm{n}$ : number of seeds.

for a number of varieties over the period 1954-1960 clearly revealed a relation between the degree of abortion and the flowering date. These results, already published earlier (Braak, 1962), are presented in Fig. 2. They show that:

- the embryo quality improves as flowering occurs earlier in spring;

- the response to the favourable effect of early flowering is larger in early varieties than in late ones.

Observations in subsequent years have shown, however, that in certain years, despite early flowering, a clear tendency to embryo abortion could occur. From this it was concluded that besides the effect of the flowering date one or more other factors played a part.

\section{Effect of temperature}

A first indication of the existance of a temperature effect was obtained in 1961 by an examination of cherry stones from a temperature experiment made in the phytotron by L. Smeets for another purpose. These seeds came from potted trees of the seedling stock Limburgse Boskriek which during fruit development had stood at constant temperatures of $14,17,20$ or $23{ }^{\circ} \mathrm{C}$ in glasshouses of the phytotron. Limburgse Boskriek is a seedling stock derived from the wild sweet cherry. It has a long period of fruit development and normally produces well developed embryos. It was found that the seeds grown at 23,20 and $17^{\circ} \mathrm{C}$ contained almost exclusively fully 
developed embryos, whereas an appreciable percentage of the seeds grown at $14{ }^{\circ} \mathrm{C}$ yielded aborted embryos.

To obtain a confirmation of the above results, in 1962 two temperature experiments were carried out in which potted trees of the early variety Kassin's Frühe and of the late ripening seedling rootstock Limburgse Boskriek, after having flowered in the field, were placed in the phytotron at a range of constant temperatures until the fruits were ripe. The results are presented in Fig. 3 and 4 in the form of frequency graphs. It appeared that both varieties produced well-developed embryos at higher temperatures but that below a certain temperature level - somewhere between 17 and $20^{\circ} \mathrm{C}$ - embryo quality deteriorated to a noticable degree as was shown by a decrease of the percentage of embryos with high $Q$ values and the occurrence of embryos with very low $Q$ values. Moreover embryo quality of the early variety was found to be somewhat less than that of the late ripening form over the whole temperature range.

It may be tentatively concluded that:

1. a higher temperature has a favourable effect on embryo development;

2. an early variety is more sensitive to this effect than a late variety.

On the basis of the results described above and in the preceding chapter it would be possible to formulate a general advice for the improvement of the embryo quality of early varieties of sweet cherry. The expectation is justified that by placing potted mother trees in spring in a glasshouse kept at $20^{\circ} \mathrm{C}$, both by advancement of the

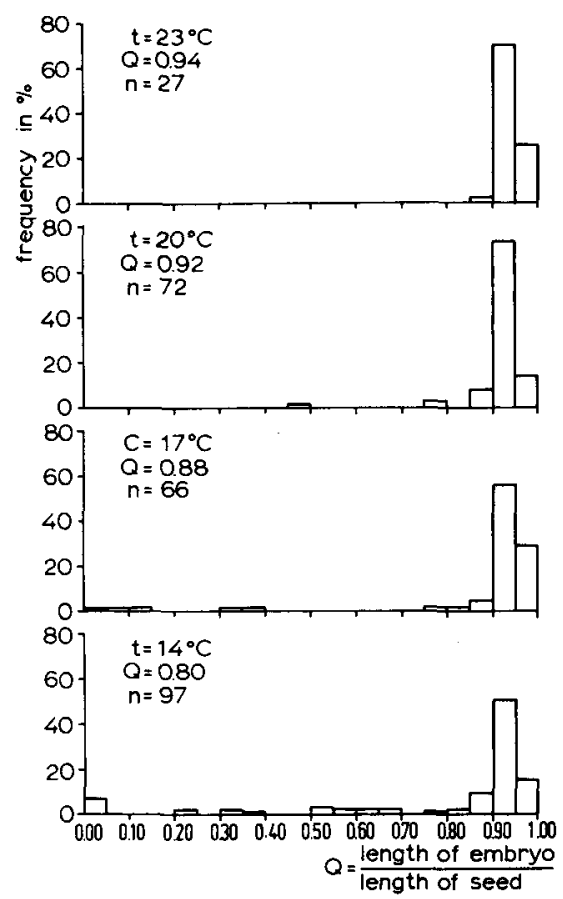

Fig. 4. The distribution of developmental index classes of embryos of the late ripening seedling rootstock Limburgse Boskriek grown at 4 constant temperatures. $t$ : temperature; $Q$ : mean developmental index; $n$ : number of seeds. 
flowering date and by the relatively high temperature, embryo development will be promoted and consequently germinability of the seed increased.

It was, however, considered desirable, both for designing a really efficient treatment to prevent abortion in early varieties and for a better understanding of the process of embryo development in sweet cherry in general, to continu the research.

For this purpose the following two questions had to be answered:

1. Is the temperature effect active throughout embryo development or only for a short sensitive period?

2. Are the observed effects of flowering date and temperature of common occurrence in the species Prunus avium L.?

In the next section the experiments regarding question 1 are discussed, in the second next section those regarding question 2 .

\section{Research of a temperature-sensitive period and calculation of heat sums for phases I and II}

In an experiment aimed at detecting a possible temperature-sensitive period, potted trees of the early variety Kassin's Frühe and the very early variety Früheste der Mark, after having flowered outside, were distributed among two glasshouses with constant temperatures of 17 and $20^{\circ} \mathrm{C}$, respectively. As has been shown above, these temperatures lie in the transition zone between favourable high and unfavourable low temperatures. Therefore it might be expected that even a small cold shock within a possible sensitive period would induce a clearly observable abortion.

Per temperature the trees of each variety were divided into 4 groups. The number of trees in each group varied between 1 and 8, depending on the size and available number. The plants of 3 groups received a cold shock - in each group at a different time during embryo growth - by transfer to a climate room at $10^{\circ} \mathrm{C}$ for 5 days. The 4th group served as the control. After ripening of the fruits in the glasshouses the quality of the embryos was determined per group of trees.

As it was intended to apply the cold treatment in the 4 variety-temperature combinations (Kassin's Frühe at 17 and $20^{\circ} \mathrm{C}$, Früheste der Mark at 17 and $20^{\circ} \mathrm{C}$ ) at corresponding moments during embryo development, it was necessary to predict with sufficient accuracy some fixed points of this development, notably the end of phase I and the completion of embryo growth at the end of phase II. This proved feasible by using the heat sums calculated for the period of phase I and for the period of phase II.

In previous years the chronological sequence of embryo development in the field had been established for 6 varieties from periodically collected fruit samples. By combination of these data with those on outside temperatures recorded in the periods concerned, heat sums could be calculated for phase I and phase II.

In applying heat sums, a linear relationship is assumed between the rate of a growth process and the temperature above a certain base temperature or threshold value. About a base temperature relating to embryo growth of the cherry, no data were available. Therefore this value was assessed by determining from the available field data of the above-mentioned 6 varieties the heat sums with their standard de- 
viations for phases I, II and I + II for all threshold values of $+1{ }^{\circ} \mathrm{C}$ up to $+9{ }^{\circ} \mathrm{C}$. As the standard deviation proved to be smallest with a threshold of $+6{ }^{\circ} \mathrm{C}$, this base was used in further calculations. This figure corresponds rather well with values of $+4{ }^{\circ} \mathrm{C}$ up to and including $+10{ }^{\circ} \mathrm{C}$ mentioned in the literature for various growth processes of fruit crops, and with the value of $+5{ }^{\circ} \mathrm{C}$ calculated for flower bud development in sweet cherry (Anstey, 1965).

The heat sums calculated for the six varieties mentioned using $+6{ }^{\circ} \mathrm{C}$ as the threshold are presented in Table 1 . There appeared to exist reasonable agreement, both between the years within the same variety and between the varieties.

An idea of the reliability of the heat sum calculations concerned can also be obtained by comparison of the embryo growth curves of Fig. 5 and 6 . In these the embryo growth in the field of the late variety Bastaarddikke of five years is plotted against the number of days (Fig. 5) and against the number of heat units (Fig. 6) after full bloom. Whereas in Fig. 5 the points both of the start and the end of the phase of rapid embryo growth lie mostly far apart, they coincide surprisingly well in Fig. 6.

Before starting the experiment described at the beginning of this chapter, the exact dates of the end of phase I and of phase II were determined by means of heat sum computations based on the flowering dates of the varieties Kassin's Frühe and Früheste der Mark and on the temperatures of 17 and $20^{\circ} \mathrm{C}$ in the glasshouses. Taking into account the standard deviation of Table 1 , it was to be expected that the chance of the error remaining within the limits of $1 \frac{1}{2}$ days before and after the calculated dates is $95 \%$.

Using the dates thus obtained as points of reference, in each of the 4 varietytemperature combinations cold shocks of 5 days at $+10^{\circ} \mathrm{C}$ were given, at the end of phase I to one group of plants, shortly before and after that moment to 2 other

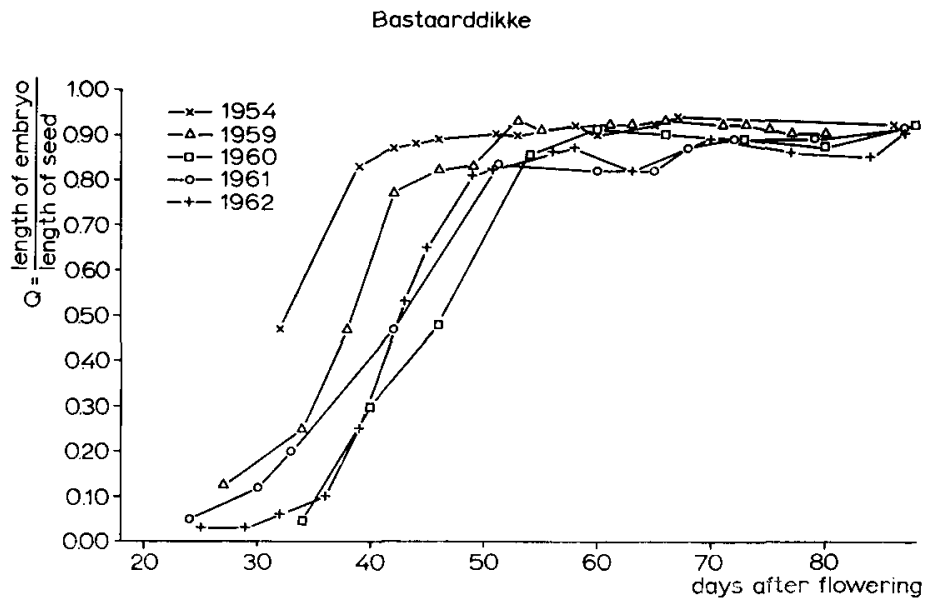

Fig. 5. Embryo development of the late variety Bastaarddikke in 5 different years. Time measused in days after flowering. 
Bastaarddikke

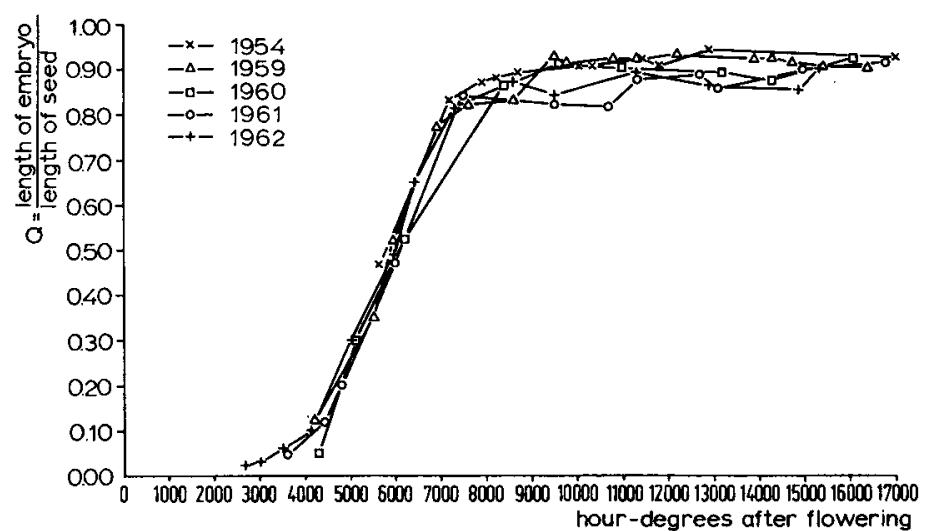

Fig. 6. Embryo development of the late variety Bastaarddikke in 5 different years. Time measured in accumulated heat units (hour-degrees above $+6^{\circ} \mathrm{C}$ ).

groups, and at the time of fruit ripeness to the control group. Afterwards the ripe fruits were collected and the mean developmental index determined for each of the 16 experimental lots. The results are shown in Fig. 7.

In the lower part of the figure normal embryo growth of a late ripening variety, showing the 3 phases of embryo growth, is plotted against a scale of heat units. In

Table 1. Heat sums in hour-degrees above $+6{ }^{\circ} \mathrm{C}$ for phase I, II and I + II of 6 varieties in different years.

\begin{tabular}{lcccc}
\hline Variety & Year & \multicolumn{3}{c}{ Heat sum in hour-degrees } \\
\cline { 2 - 5 } & & Phase I & Phase II & Phase I + II \\
Früheste der Mark & 1954 & 3900 & 4500 & 8400 \\
& 1960 & 3900 & 4300 & 8200 \\
Seneca & 1961 & 3900 & 4500 & 8400 \\
& 1959 & 3900 & 4000 & 7900 \\
Bastaarddikke & 1960 & 4100 & 3900 & 8000 \\
& 1961 & 4200 & 3600 & 7800 \\
& 1954 & 3600 & 3900 & 7500 \\
Early Rivers & 1959 & 3600 & 4400 & 8000 \\
Kassin's Frühe & 1960 & 3900 & 4200 & 8100 \\
Mierlose Zwarte & 1961 & 3700 & 4200 & 7900 \\
Mean heat sum & 1954 & 4000 & 3800 & 7800 \\
Standard deviation (S) & 1965 & 4200 & 3900 & 8100 \\
& 1965 & 4100 & 4100 & 8200 \\
\hline
\end{tabular}


the upper part the mean developmental indices of the 16 experimental groups are plotted against the same scale. By interconnecting the $4 \mathrm{Q}$ values in each of the 4 variety-temperature combinations, an indication is obtained of the developmental stage in which the cold shock had its strongest effect, viz. at the transition from phase I to phase II.

From these results the following tentative conclusions may be drawn:

1. Indeed, a sensitivity to temperature exists during part of the period of embryo development, showing a maximum at the transition from phase I to phase II.

2. Confirmation was obtained of an observation made earlier in this study: the sensitivity to temperature of variety generally increases as the period from flowering to fruit ripeness is shorter.
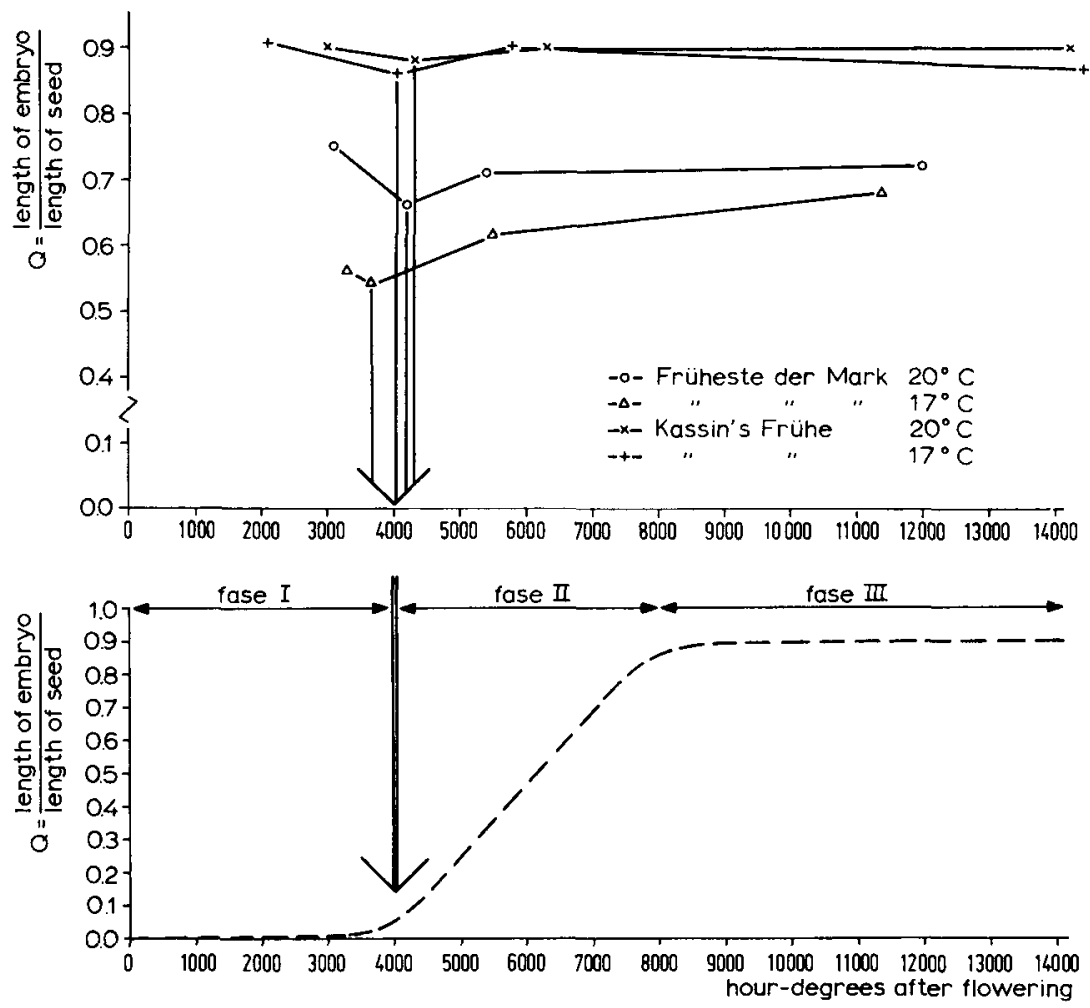

Fig. 7. Effect at fruit ripeness of a low temperature shock of 5 days at $+10^{\circ} \mathrm{C}$ on embryo quality. Below: Normal embryo development showing 3 successive phases I, II and III. Above: Effect of a low temperature shock given at three different moments during embryo development of 2 varieties grown at constant temperatures of 17 or $20^{\circ} \mathrm{C}$. 
Table 2. Sweet cherry varieties listed in order of increasing length of the fruit development period.

\begin{tabular}{lll}
\hline Variety & $\begin{array}{l}\text { Average duration of } \\
\text { fruit development } \\
\text { period in days }\end{array}$ & $\begin{array}{l}\text { Average value of } \\
\text { developmental index of } \\
\text { embryo at fruit ripeness }\end{array}$ \\
Seneca & 50 & \\
Früheste der Mark & 52 & 0.47 \\
Kassin's Frühe & 59 & 0.42 \\
Early Rivers & 61 & 0.81 \\
Wijnkers & 66 & 0.79 \\
Ohio Beauty & 70 & 0.77 \\
Inspekteur Löhnis & 71 & 0.75 \\
Sprenkelkers & 73 & 0.76 \\
Mierlose Zwarte & 75 & 0.70 \\
Black Tartarian & 76 & 0.75 \\
Schneiders Späte Knorpelkirsche & 79 & 0.76 \\
Giant & 80 & 0.82 \\
Elton & 82 & 0.81 \\
Bastaarddikke & 84 & 0.73 \\
Udense Spaanse & 86 & 0.88 \\
\hline
\end{tabular}

Is the combined effect of flowering date and temperature a phenomenon of general occurrence in the sweet cherry?

Although from the experimental results discussed above a reasonable degree of certainty had been obtained regarding the existence of an effect of flowering date and temperature, and the occurrence of these phenomena had been mentioned tentatively in previous publications (Braak, 1962, 1965), it was realized that research had hitherto been confined to a limited number of varieties. It was, therefore, thought advisable to extend the study to a larger number of varieties under different environmental conditions before recommending an efficient and dependable method for the prevention of embryo abortion.

To achieve this, available field data on embryo quality of 15 varieties from 1954 up to and including 1965 (see Table 2) were made accessible for an investigation of the relationship between, on the one hand, flowering date and temperature, and on the other, embryo quality. The procedure followed is outlined below.

1. First the relation was established between the temperature during the sensitive period and the embryo quality at fruit ripeness.

2. Then it was investigated to what extent the above relationship was influenced by the flowering date.

1. For each year for which a figure for embryo quality of a variety growing in the experimental garden was available, the dates for the start, the point of maximum sensitivity and the end of the sensitive period were fixed by means of heat sum calculations. This was done by using the flowering date as a point of reference and by putting the start, the point of maximum sensitivity (see Fig. 7) and the end of 
the sensitive period respectively at 2750,4000 and 9250 hour-degrees after flowering. In a similar manner the points were dated that were required for the calculation of the weighted mean temperature during the sensitive period according to the following formula:

$$
\mathrm{T}=1 / 2\left[\left(\mathrm{t}_{\mathrm{a}}+\mathrm{t}_{\mathrm{b}}+\mathrm{t}_{\mathrm{c}}\right) / 3+\left(\mathrm{t}_{\mathrm{d}}+\mathrm{t}_{\mathrm{e}}\right) / 2\right] .
$$

It is based on the experimental information presented in Fig. 7 and obtained its final form after a number of variations had been tested with the aid of the available data on temperature and embryo quality. It is so constructed that the weight of the temperature of each part of the sensitive period is expressed in the figure in accordance with the sensitivity of that part. Thus a value for the weighted mean of the temperature during the whole sensitive period is obtained. The meaning of the symbols in the formula is given below:

$\mathrm{T}=$ weighted mean temperature of the total sensitive period from 2750 to 9250 hour-degrees after flowering;

$t_{\mathrm{a}}=$ mean temperature of the period from 2750 to 5250 hour-degrees;

$t_{b}=$ mean temperature of the period from 3250 to 4750 hour-degrees;

$t_{c}=$ mean temperature of the period from 3750 to 4250 hour-degrees;

$\mathrm{t}_{\mathrm{d}}=$ mean temperature of the period from 5250 to 9250 hour-degrees;

$t_{e}=$ mean temperature of the period from 5250 to 7250 hour-degrees.

A comparison of the weighted temperature means thus calculated with the figures for embryo developmental index of the individual varieties in the corresponding years revealed a general association between higher temperature and good embryo quality, but deviations from this rule also frequently occurred.

2. Therefore it was ascertained whether these deviations could be due to the effect of the flowering date on the embryo quality (see Fig. 2). To this end a diagram was made for each variety, in which the calculated weighted mean temperature was plotted against the developmental index on the vertical axis and against flowering date on the horizontal axis, marking each plotted point with the calculated temperature and with the year concerned. The diagram for the variety Giant may serve as an example (Fig. 8).

The diagrams of all varieties investigated showed a similar picture. It appeared that, although the $Q$ value was generally larger at higher temperatures, it decreased when flowering shifted to a later date. This combined effect of temperature and flowering date is demonstrated more clearly if, by the use of the experimental points in the diagram, lines representing a series of temperatures are drawn, as has been done in Fig. 8 in the diagram for Giant.

For a separate analysis of one of the two effects on embryo development the action of the other must be excluded. Below a method for examination of the temperature factor is outlined in which the influence of the flowering date is eliminated by transforming all $Q$ values for one and the same mean flowering date. From the flowering dates of all 15 varieties in the years 1954 to 1965 a mean date of flowering on 25 April was calculated. In each variety diagram, on the date of 25 April, a vertical line was erected. Subsequently, from each point representing an annual ob- 


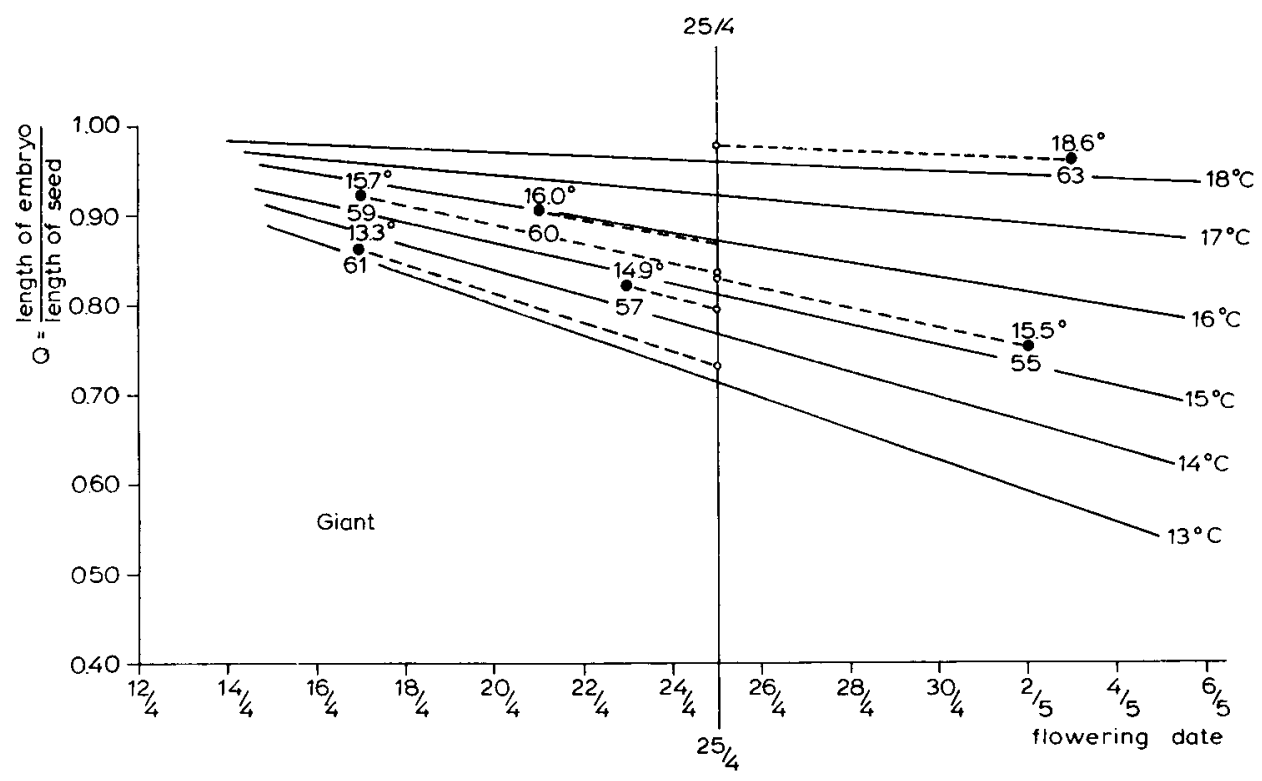

Fig. 8. Diagram showing the combined effect of flowering date and temperature on embryo quality for the variety Giant in 6 different years. The intersections of the dotted lines with the vertical line of 25 April indicate the $Q$ values that would have been found if flowering had taken place on 25 April in the years concerned.

servation an auxiliary line was drawn parallel to the adjacent temperature line until it met the vertical of 25 April (see Fig. 8 for the variety Giant). These points of intersection indicate the $Q$ values, to be read from the $Y$ axis, that would have been found if flowering had occurred on 25 April. By plotting these $Q$ values on a graph of which the $\mathrm{X}$ axis indicates the temperature during the sensitive period and the $\mathrm{Y}$ axis the $\mathrm{Q}$ value, it can be shown how in the variety concerned the embryo quality responds to the temperature in the sensitive period for a flowering date of 25 April.

The above method was used in 3 cases for comparing the temperature response of cherry varieties, in order to establish whether this is a general phenomenon in sweet cherry which retains its character under varying conditions.

First the responses in a number of years of the mid-season variety Inspekteur Löhnis and the late variety Bastaarddikke were compared under field conditions. The results are given in Fig. 9. From the graph it appears that:

- in both varieties the embryo quality decreases when the temperature in the critical period falls below a certain value;

- the earlier ripening variety responds much more markedly than the late ripening variety.

So under field conditions there exists no fundamental difference with respect to the temperature response, but there is a difference in degree between an early and a late variety. 


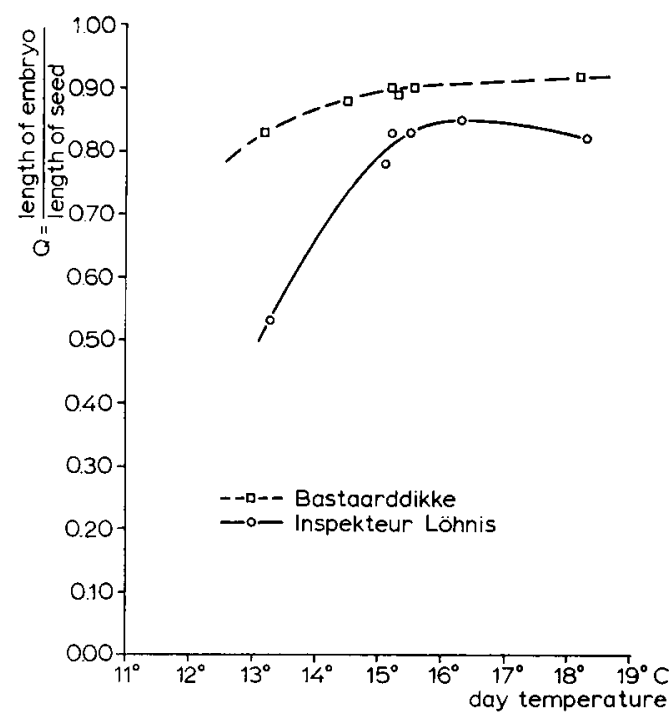

Fig. 9. Comparison of a mid-season variety (Inspekteur Löhnis) and a late variety (Bastaarddikke) with regard to the reaction of embryo quality to temperature.

Next the temperature response of one and the same variety under two different sets of environmental conditions was compared. For the very early variety Fruheste der Mark calculations were made on the basis of data from field observations extending over 8 years, and from 11 temperature experiments in the phytotron. The figures obtained demonstrated clearly that in both environments the embryo quality fell off rapidly when the temperature dropped below a certain value. The bending point in the curve of the phytotron experiments, however, lays between 16 and $18^{\circ} \mathrm{C}$ and in that of the field observations between 14 and $15^{\circ} \mathrm{C}$.

Until then the calculations of the weighted mean temperatures during the sensitive

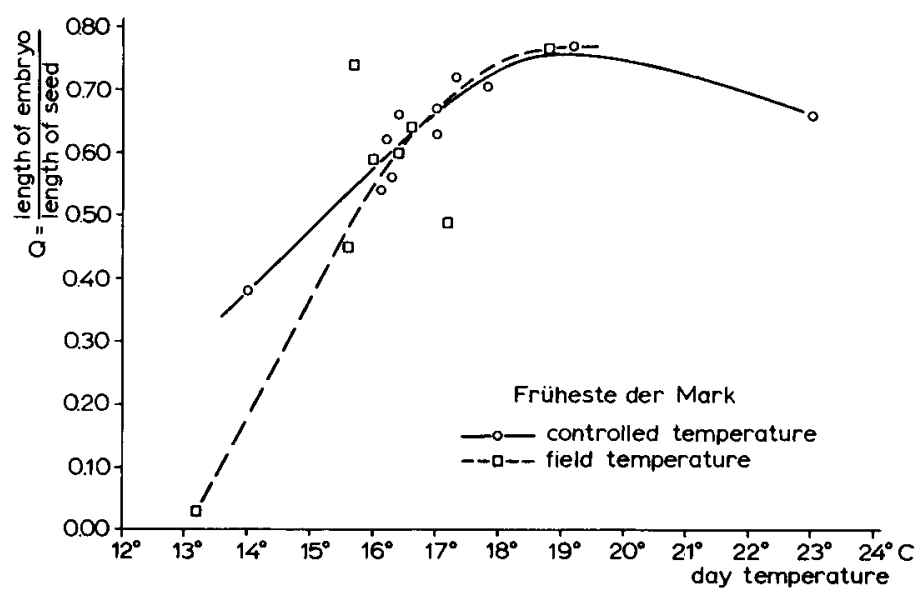

Fig. 10. Comparison of the reaction of embryo quality to temperature under two different sets of environmental conditions in the very early variety Früheste der Mark. 
period were always based on diurnal temperatures. It was, however, found that if the calculations were based on day temperatures (between 06h00 and 18h00) instead of 24-hour temperatures, the transition from favourable to adverse temperatures was located at 16 to $18{ }^{\circ} \mathrm{C}$ for both environments, as is demonstrated in Fig. 10 .

Without further experimental data no definite choice can be made between the following two possible explanations for the above-mentioned difference in temperature response: either the special conditions in the prytotron (high night temperature, reduced light intensity, constant humidity) cause increased sensitivity to low temperature; or it is the day temperature and not the diurnal temperature which is decisive for the embryo development. For the present the second possibility is assumed as the correct one because it is the simplest explanation. Therefore all calculations mentioned hereafter are based on the day temperature. It should be noted that the graphs of Fig. 8 and 9 have also been constructed on the basis of day temperatures.

The conclusions from his second comparison can now be formulated as follows: - Presumably embryo development is determined by the day temperature and not by the 24-hour temperature.

- Both under field conditions and under controlled environmental conditions the embryo quality falls off rapidly when the day temperature during the critical period drops below $16-18{ }^{\circ} \mathrm{C}$.

Finally it was investigated wether the temperature response, which manifested

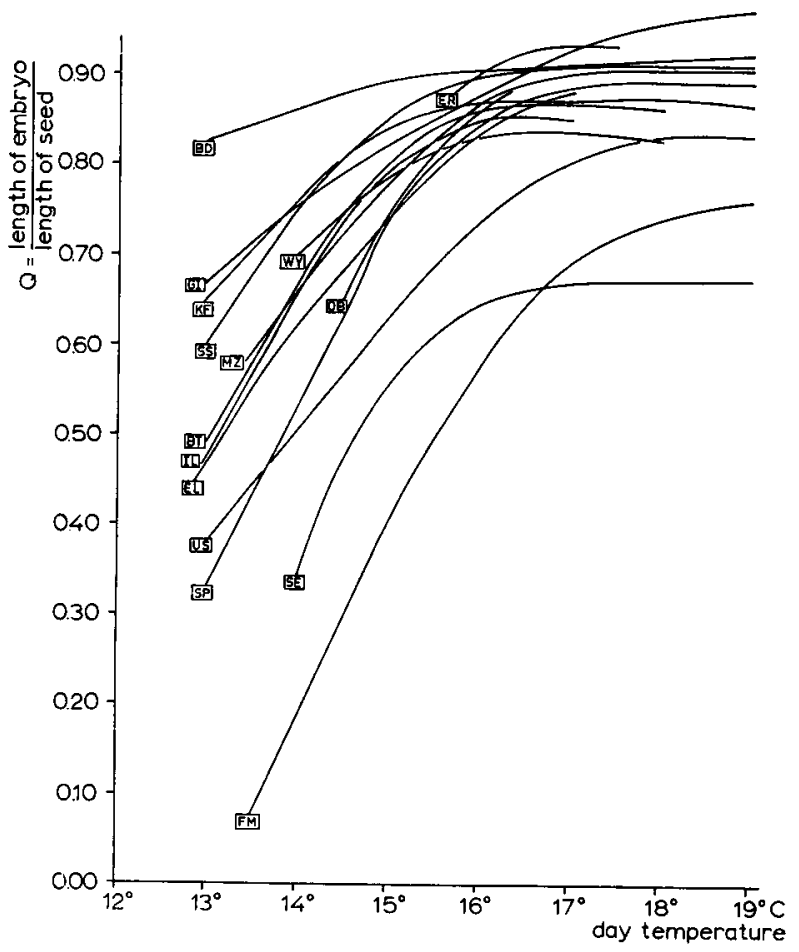

Fig. 11. Comparison of the responses of embryo quality in 15 sweet cherry varieties to temperature during the critical period under field conditions. ER: Early Rivers; BD: Bastaarddikke; WY: Wijnkers; GI: Giant; KF: Kassin's Frühe; SS: Schneiders späte Knorpelkirsche; OB: Ohio Beauty; MZ: Mierlose Zwarte; BT: Black Tartarian; IL: Inspekteur Löhnis; EL: Elton; US: Udense Spaanse; SP: Sprenkelkers; SE: Seneca; FM: Früheste der Mark. 
itself so characteristically and consistently in some varieties, occurs more generally in the sweet cherry. For this purpose temperature response curves were calculated for those varieties present in the experimental garden of which data over at least 4 years were available. In all 15 varieties were involved; they are listed in Table 2. The 15 response curves are presented jointly in Fig. 11.

The close agreement between all curves is very striking. The following conclusions may elucidate the general picture:

- There is a close agreement between the responses of the varieties as regards the manner in which an optimum embryo quality is maintained above a certain temperature and in which the developmental index of the embryo falls off more or less rapidly below this temperature.

- Roughly speaking, the transition between favourable and unfavourable temperatures for all 15 varieties lies at the same temperature level, viz between 16 and $18{ }^{\circ} \mathrm{C}$.

- The optimal developmental index achievable at favourable temperatures generally lies higher in late ripening than in early ripening varieties.

Summarizing, it can be postulated that a characteristic response of embryo development to temperature in sweet cherry varieties has a general distribution.

\section{Discussion and conclusions}

The research was aimed at finding a solution to the problem of poor seed germination in early cherry varieties, which could serve as an alternative to the use of embryo culture. The consideration that it might be possible to improve embryo development by means of an effect of environmental factors on the mother tree was the starting point of the investigation.

The experimental results have shown that this line of thought was correct. It was established that the growth of the embryo is influenced both by the flowering date of the mother tree and by the temperature during embryo development: early flowering and high temperature have a favourable effect, late flowering and low temperature an adverse effect.

It is not clear what specific environmental factor is responsible for the effect of the flowering date. Possibly the shorter day length connected with earlier flowering has a favourable influence. An indication of such an effect has been provided by a study of embryo development in the apple (Braak, 1962).

It was found that in all varieties investigated the temperature exercises an influence during part of the period of embryo growth with an optimal effect at the transition from phase I to phase II. It was also established that there was always a critical temperature above which an embryo quality optimal for the variety concerned is maintained, but below which this quality deteriorates more or less rapidly. Finally, it was shown that under different environmental conditions the transitional temperature always lies in the same region, between 16 and $18{ }^{\circ} \mathrm{C}$. This assumption of a constant critical temperature applies with the proviso that the calculations are not based on diurnal temperatures but on day temperatures.

On the basis of the experimental results obtained the following method of pre- 
venting or reducing embryo abortion in early cherries can be recommended. Place the potted parent trees in a temperature-controlled glasshouse a short time before flowering. After the crosses have been made, the trees from which seed will be harvested should remain in the glasshouse in which the temperature must not be allowed to drop below $18{ }^{\circ} \mathrm{C}$. The stay in the glasshouse may be terminated as soon as phase II of the embryo development is completed (8000 - 9000 hour-degrees above a base temperature of $+6{ }^{\circ} \mathrm{C}$, after flowering).

If the response of a variety to flowering date and temperature is known, it can also be predicted in what kind of climate optimal embryo development may be expected. From this it can probably be inferred which geographic region is most suitable for the execution of a breeding project for earliness.

The specific response of the separate varieties may also supply information about the climate and region of origin. It may, for instance, be assumed that an early variety, of which embryo development is very sensitive to environmental conditions can only arise in a geographic region where flowering occurs early and the temperature in the following period remains relatively high. Late varieties, which generally are less liable to embryo abortion, may have originated equally well in a less favourable climate. Information of this kind can contribute to a knowledge of the origin of wild and cultivated forms of the sweet cherry.

Finally it should be realized that an effect of flowering date and temperature on embryo quality may also be found in other stone fruits, and even in other genera of the Rosaceae. This supposition is corroborated by the fact that the usually poor embryo quality of the very early peach variety Mayflower could be markedly improved by placing the mother trees in a glasshouse in which the temperature was kept above $16{ }^{\circ} \mathrm{C}$ (Monet,, 1968).

\section{Acknowledgments}

My thanks are due to the members of the Fruit Department for recording flowering and picking dates and for collecting fruit samples over a range of 14 years, and to the members of the Statistics Department for correcting the many temperature data and making the heat sum calculations. I am particularly grateful to the successive assistants in my own department: H. C. van der Gaag, J. P. Versluijs, G. F. N. van Everdingen, Miss C. J. van der Veen and J. Franken. Only by their work, which they carried out with much devotion, perseverance and great accuracy, was the successful completion of this investigation possible. Dr L. Smeets is especially thanked for his advice and assistance with regard to the preparation of the manuscript.

\section{References}

Abou-Zeid, A., W. Gruppe \& K. H. Neumann, 1972. Eine Methode zur Anzucht normalwachsender Kirschsämlinge aus Embryoachsen. Gartenb. Wiss. 37: 399-407.

Anstey, T. H., 1965. Prediction of full bloom date for apple, pear, cherry, peach, and apricot from air temperature data. Proc. Am. Soc. hort. Sci. 88: 57-66. 
Braak, J. P., 1955. Effects of some internal and external factors on the embryo and seedling development of the cherry. Rep. 14th int. hort. Congr. (Netherlands): 845-852.

Braak, J. P., 1962. Influence of growth conditions on fruit and embryo development in apple and cherry. Eucarpia Conference Arnhem 1961. Meded. Inst. Vered. TuinbGewassen Wageningen 182: 57-65.

Braak, J. P., 1965. Invloed van het milieu op de embryo-ontwikkeling. Ann. Rep. IVT 1964. Meded. Inst. Vered. TuinbGewassen Wageningen 240: 14, 53.

Danielson, B., 1950. Embryokulturer av stenfruktträd. Sver. Pomol. Fören. Arsskr. 51: 200-206.

Davidson, O. W., 1933. The germination of 'non-viable' peach seeds. Proc. Am. Soc. hort. Sci. 30: $129-132$.

Davidson, O. W., 1934. Growing trees from 'non-viable' peach seeds. Proc. Am. Soc. hort. Sci. 32: 308-312.

Hesse, C. O. \& D. E. Kester, 1955. Germination of embryos of Prunus related to degree of embryo development and method of handling. Proc. Am. Soc. hort. Sci. 65: 251-264.

Kester, D. E., \& C. O. Hesse, 1955. Embryo culture of peach varieties in relation to season of ripening. Proc. Am. Soc. hort. Sci. 65: 265-273.

Lammerts, W. E., 1942. Embryo culture an effective technique for shortening the breeding cycle of deciduous trees and increasing germination of hybrid seed. Am. J. Bot. 29: 166-171.

Lammerts, W. E., 1943. Effect of photoperiod and temperature on growth of embryo-cultured peach seedlings. Am. J. Bot. 30: 707-711.

Lilleland, O. \& L. Newsome, 1934. A growth study of the cherry fruit. Proc. Am. Soc. hort. Sci. 32: 291-299.

Lesley, J. W. \& J. Bonner, 1952. The development of normal peach seedlings from seeds of early-maturing varieties. Proc. Am. Soc. hort. Sci. 60: 238-242.

Monet, R., 1968. Méthode permettant l'obtention de plantes viables à partir d'embryons de variétés très précoces chez le pêcher. Annls Amélior. Pl. 18: 85-91.

Remy, P., 1961. Recherches physiologiques sur la maturation des graines d'arbres fruitières à noyau. Thèse, Université Bordeaux, $197 \mathrm{pp}$.

Stösser, R., 1966. Befruchtungsbiologische und embryologische Untersuchungen bei der Süsskirsche (Prunus avium L.). Dissertation Landw. Hochschule Hohenheim, 113 pp.

Theiler, R., 1971. Embryonenkultur für die Anzucht neuer Kirschenhybriden (Prunus avium L.). Schweiz. Landw. Forsch. 10: 65-93.

Tukey, H. B., 1933a. Embryo abortion in early-ripening varieties of Prunus avium. Bot. Gaz 94: 433-468.

Tukey, H. B., 1933b. Artificial culture of sweet cherry embryos. J. Hered. 24: 7-12.

Tukey, H. B., 1934. Artificial culture methods for isolated embryos of deciduous fruits. Proc. Am. Soc. hort. Sci. 32: 313-322.

Tukey, H. B., 1938. Growth patterns of plants developed from immature embryos in artificial culture. Bot. Gaz. 99: 630-665.

Willing, H., 1960. Phänologische und chemische Untersuchungen zur Fruchtentwicklung bei Kirschen. Arch. Gartenb. 8: 561-594. 